\title{
Managing the Balance: Ecological Pressures and Heritage Resources in Rungwe District, Southern Highlands of Tanzania
}

\author{
Makarius Peter Itambu \\ Department of Archaeology and Heritage, University of Dar es Salaam, Dar es Salaam, Tanzania \\ Email: mcepeter7@gmail.com
}

Received 1 December 2015; accepted 25 March 2016; published 28 March 2016

Copyright $@ 2016$ by authors and Scientific Research Publishing Inc.

This work is licensed under the Creative Commons Attribution International License (CC BY).

http://creativecommons.org/licenses/by/4.0/

(c) (i) Open Access

\begin{abstract}
Rungwe district in Mbeya region is amongst the many areas in Tanzania which until recently have remained terra incognita in terms of ecological and archaeological research. Systematic archaeological investigations, based on heritage management and conservation have not been undertaken. In due regard, we decided to carry out the first systematic survey, documentation and recording of the heritage resources of this district. Our investigations emphasized public participation in the management and conservation of heritage resources with the involvement of local people the central focus. We were also motivated by the desire to launch community outreach programmes and establish the "Cultural-Ecological Research and Scientific Information Centre" in Masoko-Kisiba Ward. There were several meetings with the local people and the village officials to discuss plans. It was decided that the establishment of the deemed scientific and information centre would abide with the existing conservation laws in order to effectively address the strategies for protection, conservation and management of both natural and cultural heritage resources.
\end{abstract}

\section{Keywords}

Cultural Ecology, Heritage Management, Outreach Programmes, Conservation, Management

\section{Introduction}

This paper emanates from an archaeological reconnaissance conducted in Rungwe district in Mbeya region. This district is endowed with spectacular innumerable natural and cultural heritage assets that span from the Holocene to the Historical period. For more than two decades, the area has been the central focus for studies and research on climate change and biodiversity, hydrology, volcanology and geothermal activity. These researchers 
are primarily interested in natural resources, and there are little or no scientific interpretations about the effects of climate change on the cultural ecology and heritage resources of the region. Because of these thematic biases, there is a real in need to conduct archaeological surveys in Rungwe district that will explorelheritage assets. Since 2000, Dr. David Williamson of IRD_France spotted, but did not document a number of heritage assets while he was on geological expeditions with other colleagues from the University of Dar es Salaam, Tanzania. Our purpose is to work collaboratively to document these assets in particular.

After various heritage resources were recorded, documented and analyzed, a two-day workshop was held at Masoko area whereby the village officials and the local people were invited to discuss aspects of environmental management as well as matters pertaining to both natural and cultural heritage management. The aim was to make the local people value and appreciate their heritages so that they would help us in the promotion of tourism in the southern Tanzania circuit. We discussed and shared our experiences with local people about volcanic and climatic activities over time and space that affected their cultural landscape. Such environmental issues were underscored by involving the traditional leaders such as the chiefs and sub-chiefs in discussions in order to raise and assess community awareness.

As a result of this project, we accomplished the following goals:

- Developed collaborative, community-based joint strategies for environmental, conservation, and cultural heritage management.

- Explored the effects of different land uses on biodiversity and ecosystem services delivery at various spatial and temporal scales.

- Suggested potential management strategies for sustainable future land uses in the study region.

\section{Background Information of the Study Area}

Lying between $9.26^{\circ} \mathrm{S}$ latitude and $33.68^{\circ} \mathrm{E}$ longitude, Rungwe is one of eight districts forming the Mbeya region of Tanzania. It is bordered to the North by Mbeya Rural District, to the East by Iringa region, to the Southeast by Kyela District, to the Southwest by Ileje District and to the West by Mbeya Urban district (Figure 1). The district is administratively divided into 30 wards, of which the following five were surveyed: Kisiba, Isongola, Kambasegera, Mbambo and Kilasi. According to the 2012 Tanzania National Census, the population of Rungwe District was 339,157 people. Due to the improvement of the infrastructure and people's socio-economic status, it is assumed that the population in Rungwe is currently over 400,000 people [1].

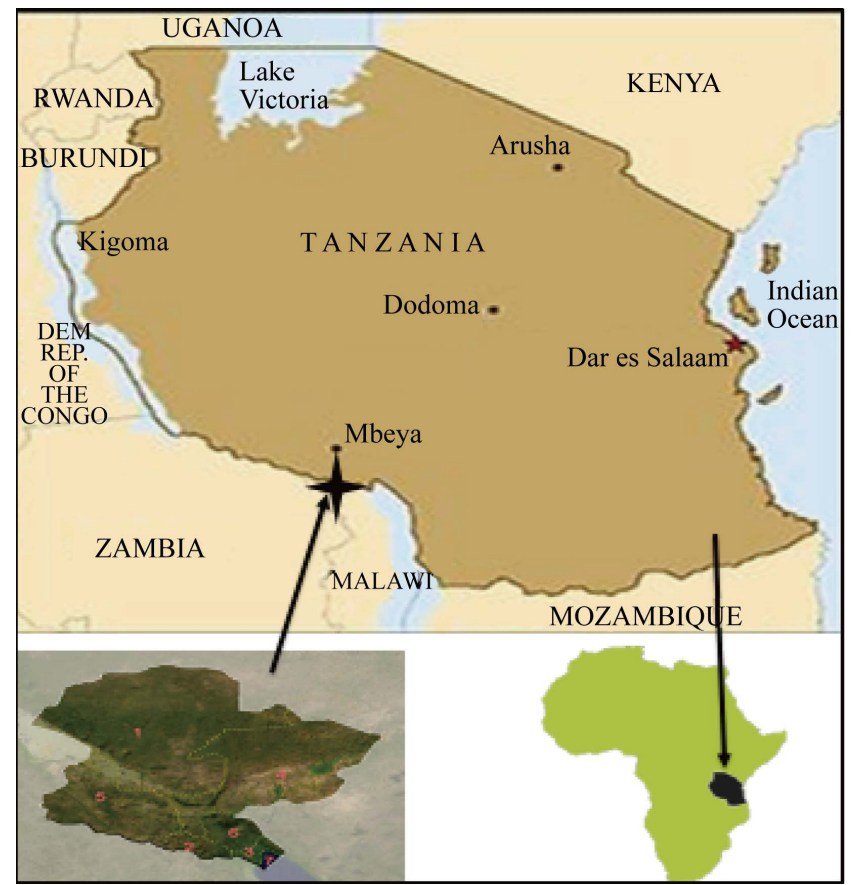

Figure 1. Map of Tanzania showing Rungwe district (Source: adapted and modified from Atlas Map of Tanzania, 2010). 
The topography of this district is characterized by the dormant volcano of Mount Rungwe at 2961 metres above sea level. Much of the district is mountainous, and contains a forest reserve that was established by the British in 1949 [1] [2]. Around Rungwe district, there are some notable but very slight tremors due to volcanic nature of the region. There is evidence of the non-dormant nature of this volcanic activity just east of Tukuyu town at Kyejo about 30 kilometers away, where carbon dioxide oozes out from the earth. Mount Rungwe is a vital river catchment area while to the east of Tukuyu town there is Kipengere Range of mountains, better known as the Livingstone Escarpment. The landscape further East becomes tremendously harsh and mountainous but suitable for some agricultural activities [3]-[5].

The climate in Rungwe district is, to some extent tropical, with marked seasons and sharply defined dry and wet seasons. The area experiences adequate rainfall throughout the year and can produce spectacular short-lived thunderstorms. The average rainfall ranges from 900 millimeters $(\mathrm{mm})$ in the lowland zone to $2700 \mathrm{~mm}$ in the highland zone. The rains normally start in October and end in May followed by dry and cold spells between June and September [1] [3]. Mean annual temperatures range between 16 degrees Celsius $\left({ }^{\circ} \mathrm{C}\right)$ in the highlands and $25^{\circ} \mathrm{C}$ in lowland areas [3] [5].

\section{Archeological and Ecological Investigations}

Previous research in Mbeya region didn't try to investigate the link between ecology and the location of the archaeological and historical sites or even to try to address the impacts of the ecology to human's adaptations to various ecological niches. They also didn't adequately explore human migration settlement distribution in the Rungwe district. Due to the varied nature of land use patterns and settlement concentration in lowland areas, as well as agricultural activities being practiced in wetland-bottom valleys, it is possible to assume that the spatial-temporal ecological instability may have triggered community's technological change and human landscape occupation strategies in different ecological zones of the region. The previous studies also neglected to explore the ecological settings of the area that characterized the archaeology of Rungwe from the Middle Stone Age (MSA) to Later Stone Age period (LSA). The MSA-LSA transition in southern Tanzania provides a unique opportunity to understand the human-environmental-interactions, technological advancement and land manipulation patterns by early humans in places other than southern Tanzania. This is especially true because the archaeological evidence from Iringa show that the southern highlands of Tanzania have been inhabited by our own species Homo sapiens for 200,000 years [6]-[8].

Although conservation studies have been virtually ignored, geological, hydrological and as well as geothermal researchers have been working in the area for many decades. For instance, volcanology and geothermal studies conducted in Rungwe [9] [10] showed records of ca. 2.2 kilometers $\left(\mathrm{km}^{3}\right)$ deposit of a Plinian-style eruption dated at ca. 4 thousand years ago (ka), a sub-Plinian one at ca. 2 ka and at least three additional smaller-scale fallout deposits. The Rungwe explosive eruptive record shows that the volcano has been frequently active in its late holocene past [9]-[11]. These investigations highlight the need for volcanic monitoring in the region and provide the basis for future volcanic hazard assessments in this province. This research put little to no emphasis on past ecological reconstruction and its interpretation in relation to human exploitation of varied niches in Rungwe from late Holocene to the present time.

The ecological settings of the Rungwe district and its adjoining areas are the present day examples of endemic plant and animal taxa that are found throughout the Zambezian-ecoregion. This is a tropical woodland that is characteristic of the modern vegetation cover of Rungwe phytochorion. With the exception of the Livingstone escapement on the east, Mt. Rungwe and Uporoto Highlands, and the Kyejo Plateau, the ecoregion is poorly conserved, and is increasingly threatened by cultivation and over-exploitation of both forest and grassland resources; activities which have already transformed large areas of the ecoregion's as a result of regular shifts from wet to drier conditions. Human settlements nowadays are concentrating in the Mabondeni (valleys), where there is a severe burning of bushes in order to clear arable land. This activity has had adverse threats to vegetation cover and its landscape. It has hindered the regeneration of many species, and some trees have been killed by the intense fires, thus opening and diminishing the woodland considerably. Early dry season bush burning, has resulted in the thickening of bushes and grasses but not the retention of woodlands. It is clear that the recent change in vegetation in many parts of Rungwe are the consequences of/or a combination of anthropogenic, physical and biological factors taking place in the region that ultimately led to the adverse ecological shifts over time and space. These factors are having a profound effect on the climate of the region which in the past was 
only influenced by physiology and altitude.

\section{Materials and Methods}

\subsection{Reconnaissance Survey and Sampling Techniques}

During the preliminary surveys, we used a digital camera for photo and video-recording and hand-held GPS receivers to document the exact locations of artifacts scattered on the landscape and relate them to their ecological settings. Also, topographic maps were used in documenting the landscape patterns and terrain in relation to discovered assets. Data collection methods depended much on in-depth interviews to locals guided by unstructured questions that were aimed at assessing general aspects of topography and other physical and ecological features. These initial exploratory archaeological and ecological investigations were aimed at paving the way for major collaborative research or multi-disciplinary research endeavors that would be conducted in the near future. Respondents were accessed through "snow-ball" sampling methods performed during the assessments of the historiography, ecological shifts and socio-economic status of the local people. This systematic recording and documentation process resulted in a detailed survey of the heritage resources of the Rungwe region. Archaeological artifacts were collected and bagged in the field; data collected were analyzed and evaluated in order to determine the current status of preservation of both natural and cultural heritage resources. This was the first step towards conservation and management of these priceless patrimonies.

\subsection{Survey Results}

Ecological, historical and archaeological evidence from the surveyed localities indicated that this part of the southern Tanzania highlands were probably occupied by human beings since the Middle Stone Age period, and are similar to some sites of the adjacent region of Iringa. Archaeological occurrences such as Later Stone (LSA) artifacts (Plate 1 and Plate 2) are scattered on the surface of the landscape. The LSA stone tools are found abundantly nearby and along water bodies, especially around the vicinity of Kisiba (Masoko), Kingiri and Kibigiri crater lakes. The recovered flakes, blades and scrapers were made from quartz lithic materials. Distribution of these archaeological artifacts nearby water bodies suggests the significant inherent linkage between water resources vis-à-vis human choice of habitats, land use patterns and the role and influence of ecology to human's subsistence strategies. These variables are mutually interdependent, sometimes are symbiotic but they are also consistently and persistently interrelated.

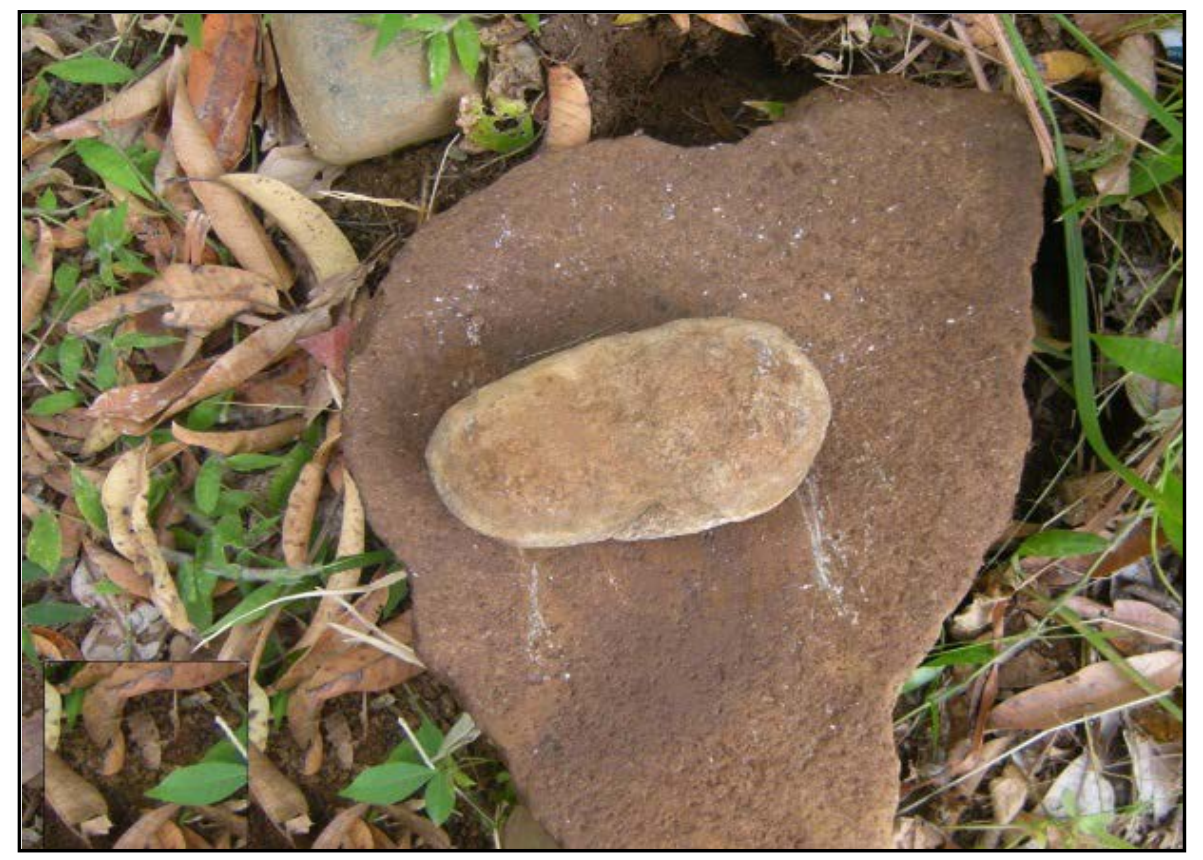

Plate 1. A grinding stone with a pestle rubber on the farmland nearby Lake Masoko. 

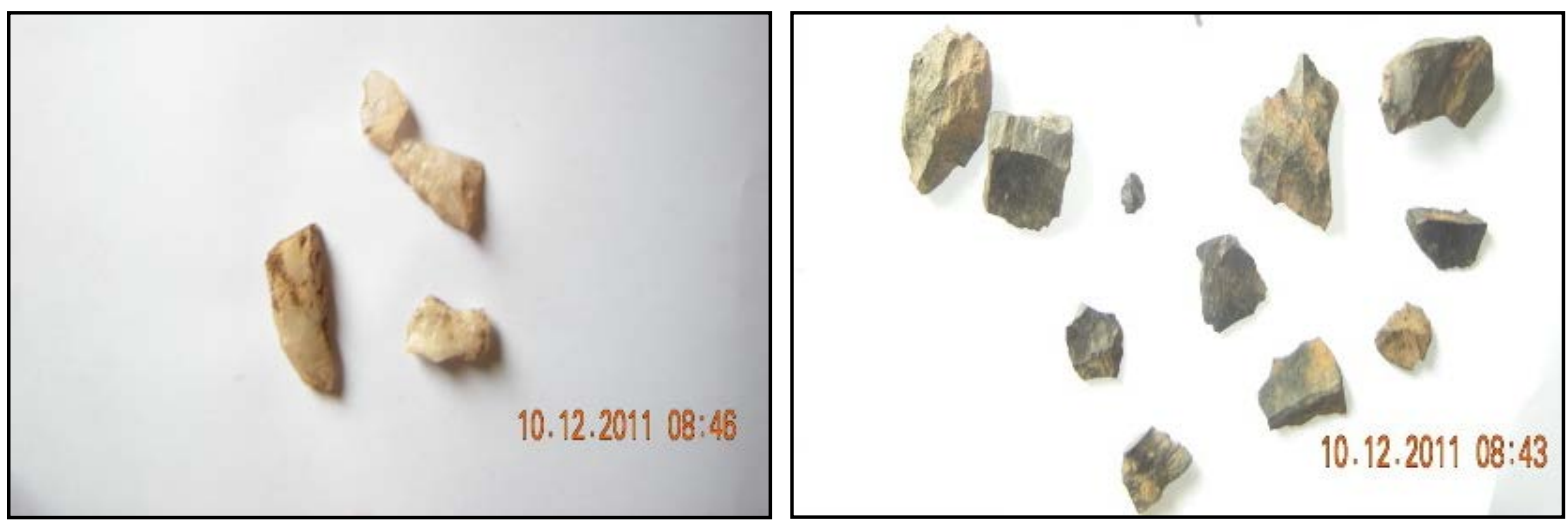

Plate 2. Flake, blade and scraper artifacts at Kingili Crater Lake.

Large scatters of prehistoric potsherds were also spotted around Kibigiri Crater Lake (S09 $24^{\circ} 971^{\prime}$ and E $\left.33^{\circ} 51^{\prime} 517^{\prime}\right)$. These pottery remains were found in association with stone tool artifacts. Likewise, we collected stone tools from the surface at Kingiri site. These lithic artifacts were small scrappers, cores, flakes and blades that were mainly made from quartz, primarily clear quartz and Bukobanian cryptocrystalline quartz (Plate 2). The existence of these surface-collected materials emphasizes the probable value of conducting an archaeological excavation in the near future to retrieve more data that will shed light on the prehistory of Rungwe district. The artifacts illustrate that the ecology i.e., water bodies could have probably influenced the prehistoric settlement locations in most parts of Rungwe district. Additionally, historical evidence revealed that pre-Colonial iron smelting was performed at Kilasi, the area whereby Lufilyo perennial river streams originates. This again supports the idea that ecological niches, water resources and landscape patterns together determine the location of ancient settlements, human socio-cultural activities and land use patterns.

\subsection{Ethnographic Inquiries on Traditional Iron Smelting at Kilasi}

Survey and ethnographic evidence collected from the local people indicated the practicability of iron smelting technology even before advent of German colonialism in Mbeya region (Mzee Mwangere pers. comm 2011) We interviewed an old man aged between 92 - 97 years, born in approximately 1918 at Kilasi village (He was told by his parents that he was born the time when Germans left the country by the end of World War II (see Plate 3 top); and he said that:

"There was a 'traditional iron smelting technology' in this village before colonialism in Tanzania, and I was a smelter having inherited the technology from my grandfather, not even from my father” (Mzee Tufwene Mwangere: Saturday, December $10^{\text {th }}$, 2011).

However, he said that the technology was only confined to the sub-clan of Wakinga, the minority who are thought to be the immigrants of Rungwe. "Ntare" in Kinyakyusa language (iron ores-both hematite $\left(\mathrm{Fe}_{2} \mathrm{O}_{3}\right)$ and magnetite $\left(\mathrm{Fe}_{3} \mathrm{O}_{4}\right)$ were obtained from Kiabugwe hill where we located some furnace remains and accessories. It appears that the iron smelting furnaces were either erected at the source of iron ore or near to the water source at Kiabugwe valley bottom. The valuable technology was protected by situating the smelting sites in hidden locations and performing the process in secrecy. In some parts of Masoko, Mbambo and Kisegese catchments, the ecology, particularly the abundance of magnetite $\left(\mathrm{Fe}_{3} \mathrm{O}_{4}\right)$ ores on the surface supported iron-smelting. The manufactured iron implements were exchanged by means of barter-trade with more productive agricultural lowland communities. The archaeological survey recovered furnace slags, clay rolls and tuyere fragments from Kilasi at Kiabugwe hill (Plate 3 bottom). The discovery of the iron smelting sites was facilitated by interviews, walkover surveys and the ethnographic inquiries. These data collection methods were useful in sites discovery because the studied area lack local chorography and relevant chronical on ancient iron smelting.

\subsection{Ecological Settings in Relation to Its Cultural Landscape}

Rungwe's rich biological, ecological and cultural diversity makes it an exceptional location for pluridisciplinary studies to examine aspects of ecology and conservation of heritage assets. Based on the ecological, cultural and 


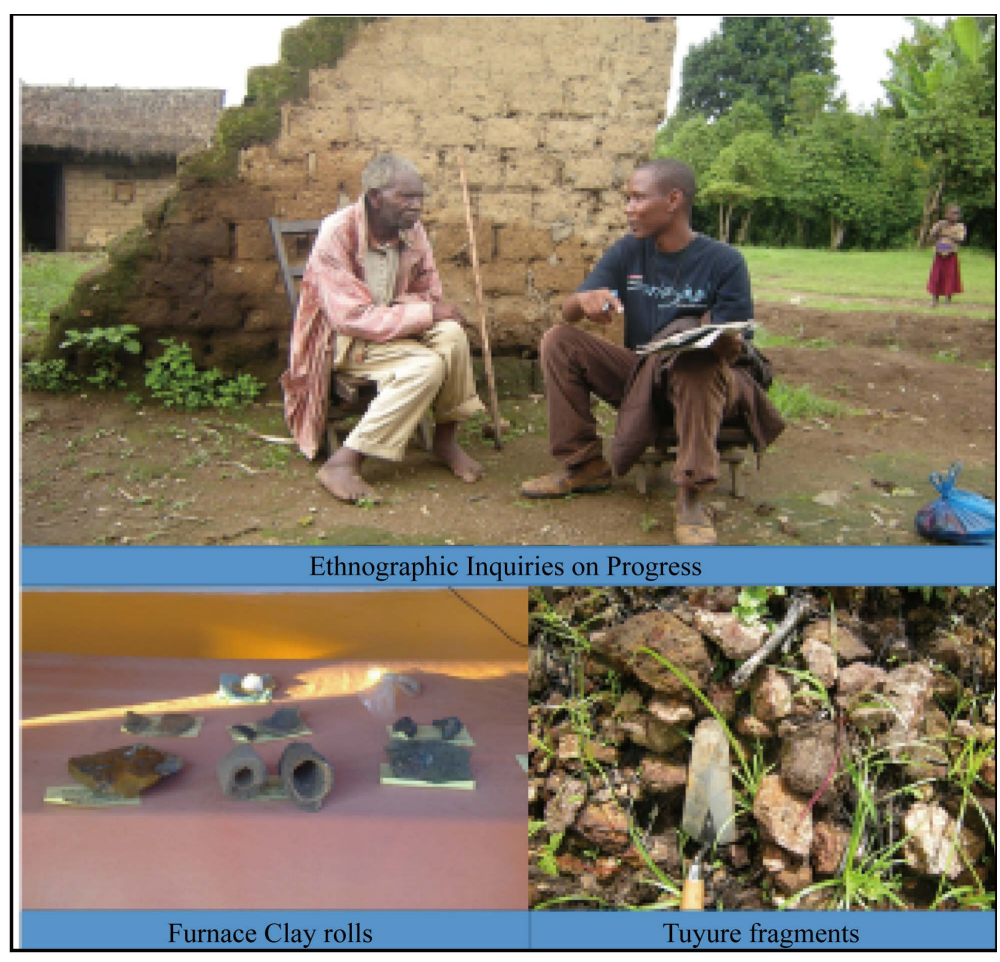

Plate 3. Ancient iron smelting at Kilasi village.

biodiversity of the district, our research exercise exposed a variety of different ecosystems. It is possible to explore the cultural landscape and flora of both the wetlands vegetation and tropical systems. This is a high rainfall zone in southern Tanzania highlands, with annual mean precipitation ranging from $700 \mathrm{~mm}$ to $2300 \mathrm{~mm}$ and lies between altitudes 600 to 2,400 m above sea level [2]. This zone extends and covers the central Mbeya plain and highlands, Ilembo and Poroto highlands. The plains include the east, central, south and west Rungwe, east Ileje as well as north Kyela. The soils are moderately fertile and consist of deep volcanic soil; deep soil over basalts, and red soils. The volcanic ashes around the vicinity of Katende and Kyejo farmlands are indicative of the recent past Holocene volcanic eruptions.

The vegetation is a mixture of acacia bushland and grassland of brachystegia woodlands. Crops grown are mainly maize, rice, pyrethrum, coffee, tea, cocoa, potatoes and beans. As mentioned, modern settlements and habitation are influenced by ecological shifts and climate change in the area. As a result of population and land pressure and diminishing pastures, pastoralism is declining while food crops cultivation is becoming the more dominant practice. This ecological shift to agricultural food production has resulted in very little free range grazing of cattle in the entire province. Very few families are keeping livestock in-doors because of depletion of open areas for grazing Also, the clearing of land has resulted in diminished forests, which along with fluctuations of waters in lakes and rivers, shrinking of water bodies, increasing aridity in lowlands areas animal husbandry is no longer supported like during the 1960s.

Rungwe's past can now be evidenced by surface collected LSA, Iron Age and historic materials that are widely distributed in many parts of the district. For instance, during reconnaissance survey around Masoko and Kingiri Crater Lakes, lithic artifacts and potsherds were recovered close to lakes and others on farmlands (Plate 2). As a result of ecological shifts early settlements concentrated around natural resource proximities such as woodlands and water bodies. The modern day's climate is generally tropical with marked seasonal and altitudinal temperature variations and sharply defined dry and rainy seasons. Changes in weather, rainfall and ecological shifts played major role in the choice, type and nature of human settlements and habitation preferences.

The importance of the ecological environment and the changes in way of life that have resulted from it can be traced via the location and type of artifacts found, such as the artifacts and potsherds located near water bodies and woodland regions. As ecological shifts occurred, the local people's technological inventions and innovations to master the natural environment also adjusted and this impacted the cultural practices and the political forma- 
tion of ancient states and chiefdoms before the colonial period. The further competition for economic resource control and changing ecological landscapes led to a change from the subsistence system to the emergence of the Chiefdom in Unyakyusaland during the $18^{\text {th }}$ century. It is clear from this impact that ecology consists of several system and subsystems or networks including the natural environment, climate and culture. These interrelated variables interact in a complex way that is significant to cultural change.

Cultural change is gradual process that caused by number of environmental proxies. Culture in a small-scale is where subsistence societies dependent in part upon it, thus it is a major contributor to social organization and to the development human institutions. Cultural ecology helps us to cross-examine spatiotemporal occurrences of archaeological and historical events (see the conceptualized example in Figure 2).

\subsection{Built Cultural Heritage Resources}

A dilapidated historic German building (Plate 4) is the most notable and significant built cultural heritage asset in Masoko area representing German $19^{\text {th }}$ Carchitectural designs in the country. At the present time, trees are over-growing on the walls and the walls are collapsing (see Plate 4), and locals are vandalizing the structure by removing bricks and stones to build their own structures. Although it is in very poor condition, it is central in the community because it houses the village offices for officials such as Ward Executive Officer, Village Executive Officer. Another building from the same time period serves as a village dispensary. Although these two buildings represent the history of German colonial rule in Tanganyika and their architectural repertoire and stylistic designs, the local people provided the labour for construction, and these buildings therefore also symbolize indigenous history, and traditions over time and space in regard to German colonial regime in Tanzania.

Unfortunately, this magnificent historic architectural beauty is under serious threat of demolition to build new offices for the village government administrators. This destruction would mean the obliteration of the historical,

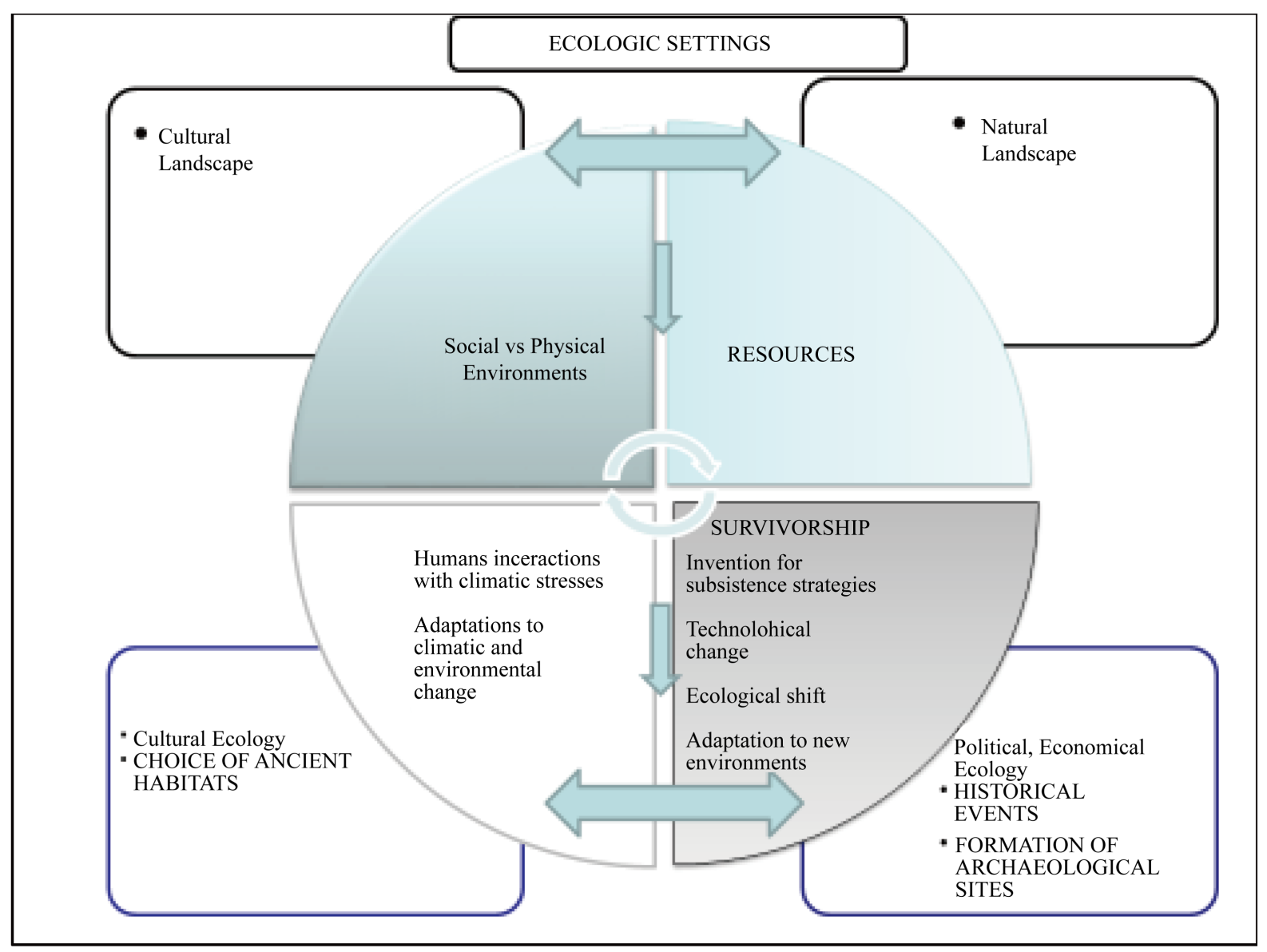

Figure 2. A schematic model (my view) on how human-ecological-interactions shapes landscape setting. 

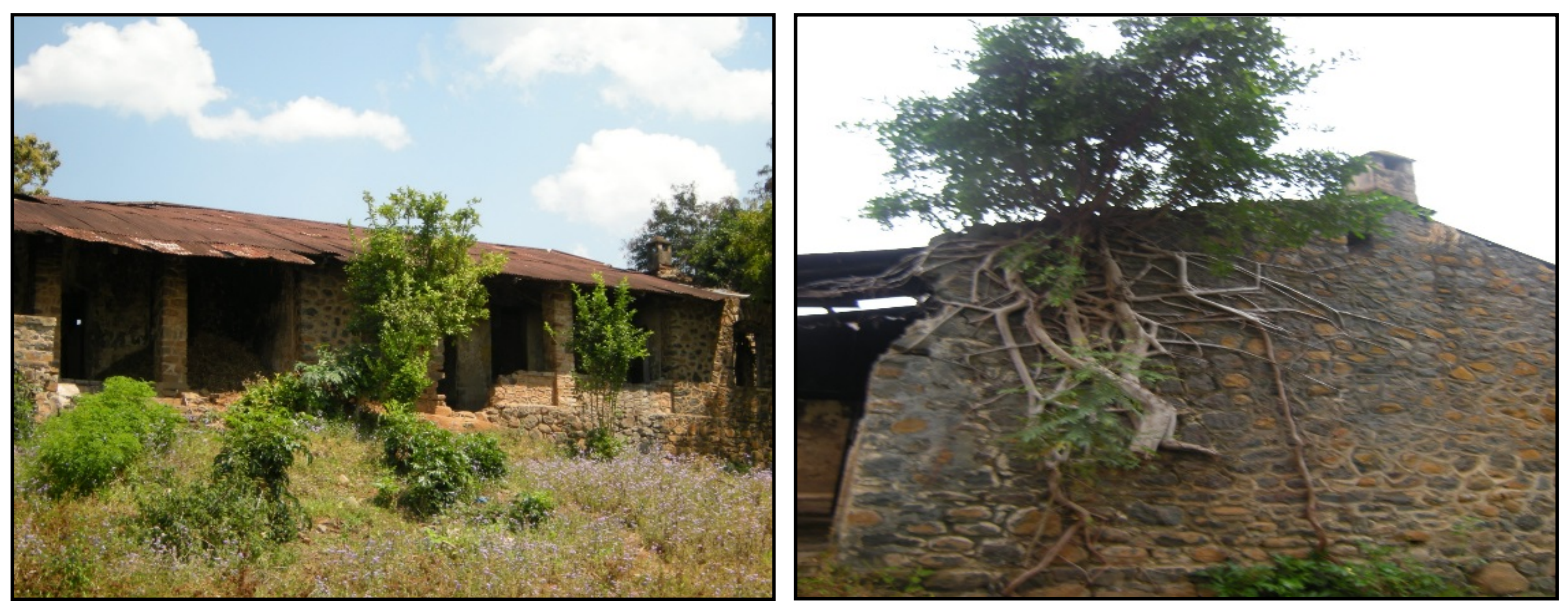

Plate 4. Deterioration conditions: trees are cropping up on the walls of the historic German Boma in Masoko.

architectural and technological heritage of German colonial rule in the region. The results from this study add a surprising wrinkle, that vandalism and demolition of the historic buildings are underway while the Ward government officials are being housed by the same Boma.

\section{Discussion}

This study demonstrated that most of the recovered, recorded or documented cultural heritage materials or resources in Rungwe are either found nearby or close to the water bodies such as rivers, streams and lakes in Rungwe landscape. It is possible therefore to deduce from this that natural ecology influenced the cultural ecology as seen in the ancient and present day settlement patterns in the district. The link between natural heritage resources vis-a-vis cultural heritage resources is clear and is interrelated because they mutually influenced occurrences of archaeological and historical sites in Rungwe. These structures and features plus their intangible elements of ecology that we call an archeological site, were at one time habitations before their abandonment by the people. In Rungwe specifically, even the modern day settlements' distribution are influenced by water sources just like the prehistoric settlements. This also demonstrates the symbiotic relationships of how prehistoric and historic people interacted with their environments and how both cultural and natural resources were key drivers and determinants of the specific locations of ancient settlements in Rungwe. Kiabugwe Hill,-where the pre-colonial iron-smelting was performed is presently the source of many ephemeral and perennial rivers in the Rungwe's montane ecotone.

The current state of preservation of the reported heritage assets varies but in some areas characterized by diminishing of water resources, forests, wild animals and traditional change in the style of building houses. It can be explained also by the poor management of both natural and cultural resources; and lack of appreciation of built heritage assets which in turn caused deterioration of the historic German Boma. These historic buildings need immediate preventive measures. The cultural landscape in Masoko is now drastically affected by fluctuations of climatic and annual rainfalls. According to interviews conducted December 2011 with Mzee Dimon Mwamugobole an inhabitant of Lwifa-Masoko Village, Lake Masoko was larger in size and volume and overflowed to cover the vegetation on the top soil in 1959 (Plate 5). The rainfall, ecology, vegetation and climatic conditions of that time are contrary from what the Lake looks like today with shrinking of lake level and decreasing of vegetation cover in the vicinity of the Crater Lake.

It can be argued, exploitation of landscape resources by humans over many centuries in this part of southern Tanzania highlands have altered natural and cultural environments, ecosystem and livelihoods. This theses corroborates with the fact that humans had witnessed huge ecological and climatic transformations and they have had been able to adapt or change the technology so that they can adjust to environmental stresses. The climatic fluctuations from wet to drier environments led to habitat shifts as evidenced by habitat preferences towards the lowland areas. This again led to abandonment of woodlands and hilltops as more favoured settlements, the places that currently have produced archaeological sites. Human activities definitely have affected the ecosystem, which is then altered, in turn affecting human socio-cultural activities. However, the shape and form of 


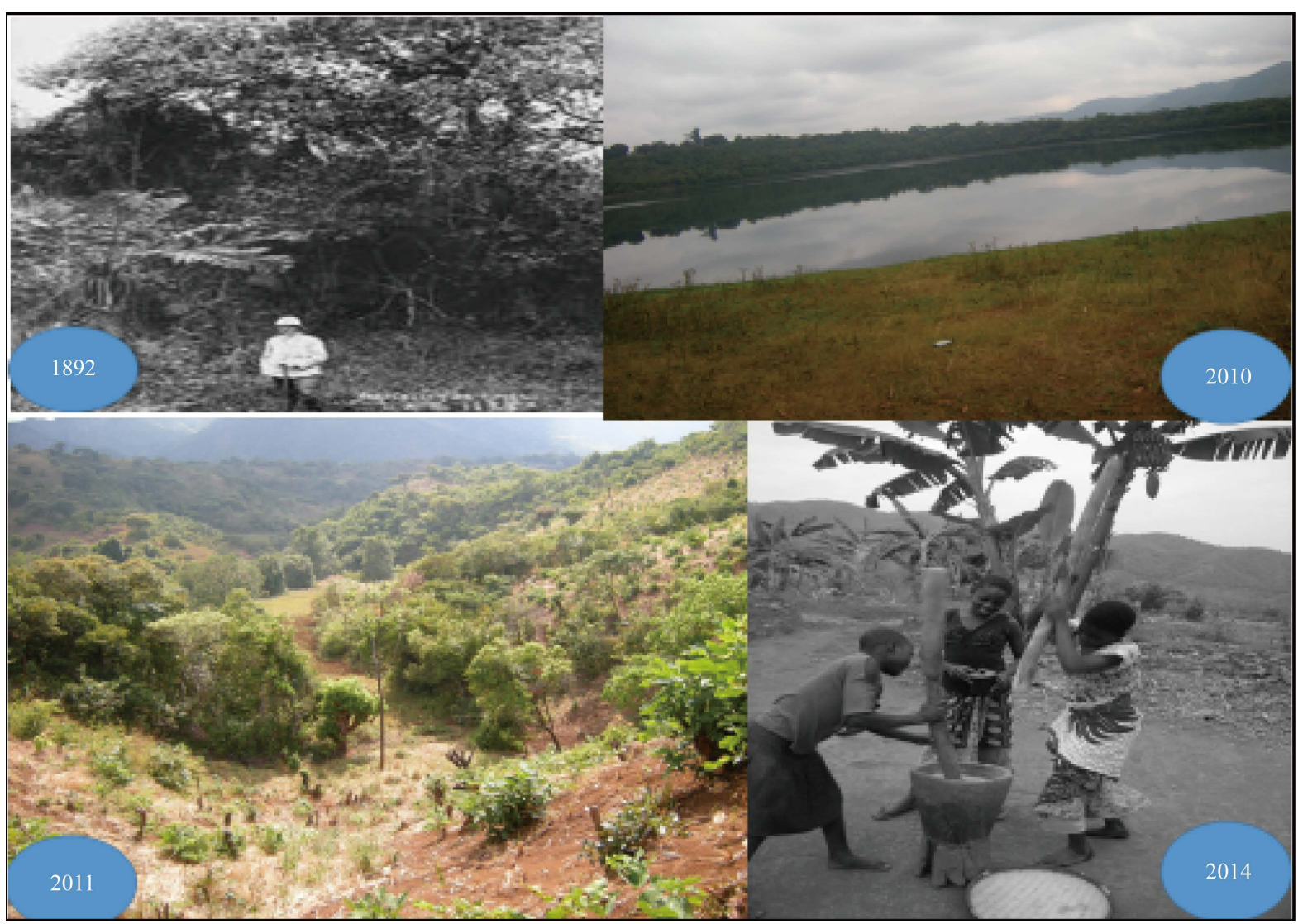

Plate 5. Ecological, landscape settings and vegetation change to the vicinity of Masoko Crater Lake from1890s-present the time.

ecology is dependent on history, a history that includes humans. Thus, it is crucially important to realize that humans are not just another animal but they are the drivers of ecology, ecological shift also triggers ecological instability or stability.

Humans are self-aware of their ecological setups, they are inherent cooperative, technological, and highly social animals. This unique combination does separate humans from other organisms, hence they can cause adverse threats to heritage resources. Generally speaking climatic change and biodiversity challenges influenced mainly by anthropogenic activities and not natural factors in the study area. More research on symbiotic relationship between culture and ecology in Rungwe will help to underscore potential issues about past subsistence problems, and shed more light on how different groups of people understand/understood their environment, and how they share their knowledge of the environment. This will aid in conservation and management of heritage resources of the district. For instance, during the 1958-1960s, the lake was a dwelling place for leopards, hyenas, antelopes, baboons and various species of monkeys but currently, one can hardly see monkeys in around Masoko Crater Lake (Mzee Dimon Mwamugole pers. comm 2011). Our field investigation results showed that in the highlands, forests and woodlands have been replaced by bushland, wooded-grassland, grassland, scrub-grassland, and induced vegetation. In others, they have been reduced to remnant patches, and small pockets on ridges and inselbergs. There have also been qualitative and quantitative changes in species composition. Some species have become more abundant and important than others due to burning, woodcutting, grazing, tree planting of native and exotic species, and the selective clearing of some species and preservation of others.

The landscape's terrain of Rungwe district, especially in Masoko-Lwifwa village, is characterized by undulating landforms and this allows for redistribution of land uses and livelihood activities. Agricultural activities now have shifted to bottom valleys that favour the rich families and allowing them to own fertile farmland while the poor manage with poor soil conditions and related poor crop productivity for the majority of people. [4] revealed that most communities settle in upper crests or upper slopes and a few of them in the bottom valleys to 
allow farming activities to take place in moderately fertile land. Valley bottoms and foot slopes are also mainly for farming activities and are potential for dry season production of maize, bean and vegetables, a pattern similar in the neighboring region of Iringa [3] [5]. The same is true for other valley bottoms in Eastern and Southern parts of Africa [3] [4]. Grazing lands are located near homesteads, where patches of grassland are found. Lands for grazing are small in size but can support improved livestock keeping (zero grazing). However, contemporary livestock keeping practices are commonly done indoors accompanied by drastic decline in livestock keeping in contrast to the free range cattle grazing of the 1990s. The main reason for the decrease of animal husbandry is the population pressure that ultimately led to the competition for the access to the arable land and the intensification of cash crops plantations. Not only agricultural activities have hindered preservation of heritage assets in Rungwe, the problem is now countrywide. Commercialization of agriculture, construction, mining, encroachment and activities of modern day civilizations have brought adverse threats to the survival of both natural and heritage assets in Tanzania.

\section{Conclusions}

For over fifty years now, ecological-heritage management, conservation and archaeological research in Tanzania have been mainly directed to the famous sites that yield paleoanthropological and paleontological remains. This situation has led to zonation biases in terms of designing research projects on ecologic-archaeological works. This study acts as a stepping stone that will provide a platform for future studies that will link heritage assets with ecology and biodiversity. This will be achieved through research partnerships and the involvement of local people in the conservation and management of these patrimonies. For the case of this study, the community involvement during the entire period of research was momentous. Already we have involved them through several meetings and workshops that we organize in three villages. The local people are able to take care of their own resources. It is important to make sure that at grassroots level there is a controlled, mechanized and well-coordinated sustainable use of the heritage assets. The focus on adaptation has a long history, but meantime it is commonly used to examine how people adjust to and cope with environmental change and uncertainty, with linkages to ideas of risk, vulnerability of both natural and cultural resources, exposure and sensitivity and their mitigation measures. For instance, land use changes can alter water resources considerably. Therefore, coupled with climatic changes, this can lead to potentially limited sustainability of agricultural practices such as irrigation. Given the intimate links between agriculture, water supply and biodiversity, strategies are urgently required to balance these variables.

\section{Future Prospects and Way Forward}

It is anticipated that this study will ease the formulation of long-term viable collaboration and multi-disciplinary research endeavors in the near future. The discussion in this paper is mainly basing on preliminary results that provide novel contribution to the heritage management scholarships in Tanzania. Therefore, Tanzanian students, researchers, stake-holders, interest groups and policy-makers should organize and launch very aggressive advertising and promotion campaigns for her heritage attractions. The main aim is to create knowledge of both natural cultural heritage attractions available in Tanzania and to encourage tourists to visit the country [12]. In regard to heritage management in Tanzania, [12] once commented that:

“Tanzania should promote a 'gentle cultural tourism' that is exotic, euphoric, community based, product oriented, long sighted, sustainable, educational, motivated by value; and a tourism in which communities participate in planning and management, and maximum revenue stays within the Country” [12]: pp. 215216.

This would be the besst kind of tourism to see the real lives of the real people, the beauty of human diversity and creativity that is evident in the incredible range of cultural practices through history. We should appreciate that we are lucky to be part of humanity. As noted earlier, the efficacy and sustainable utilization of heritage resources in Tanzania calls for joint deliberate efforts in management and conservation. Recommendations include:

1) Pluridisciplinary research will help to discover more archaeological sites and determine heritage resources vis-a-vis people's socio-economic status through time and space.

2) This cross-disciplinary research should assess climatic conditions, volcanic activities and ecological set- 
tings in regard to the heritage resources of Rungwe. These are prerequisites for furthering the assessments of land-use patterns by different population groups in Rungwe and its adjoining districts and their impacts to ecosystem and biodiversity.

3) New policies for agricultural development and sustainability should be studied by observing class dynamics (diversity and change) within the smallholder sector, and how class relationships relate to environmental stress

4) Free training to students, junior researchers and the interested people on the effect of different land use practices to the biodiversity and ecosystem services delivery at various spatial and temporal scales, would be useful, in order to encourage knowledge

5) Be able to speak and suggest on management strategies for sustainable future land uses in Mbeya region.

6) Addressing the symbiotic relationship between cultural heritage resources and environmental parameters such as water resources governance and biodiversity conservation.

Therefore, by doing so, we shall make a huge stride forward to the promotion of eco-cultural tourism to the southern corridor of Tanzania especially when the 'Scientific Information centre' will to take off. The torrential impetus of the community outreach programmes and the establishing "Cultural and Ecological Research and Scientific Information Centre" in Masoko village together will be offering pro-bono training annually to ensure sustainability in conservation and management activities.

\section{Acknowledgements}

The field research was made possible by grants from the France Institut de Recherche pour le Développement (IRD) and the Institute of Resource Assessments (IRA) of University of Dar es Salaam, Tanzania. Further thanks are due to Joshua Mwakipesile, Abdalla Issa, Ezekiah Mwandapile, Dimon Mwamugomole, Bernad Mwakisunga (RESON-Masoko), Pierre-Etienne Mathé (CEREGE) and Dr. David Williamson (Project Co-coordinator LOCEAN-IRD) who deserves to be in the uppermost acknowledgements together with his team, the Rungwe Environmental Science Observatory Network (RESON), the PAREGO/HEREGO program of the IRD, and the TECLA project of the French Fondation Nationale pour la Biodiversité (FRB), which co-sponsored my study. I also wish to acknowledge the warm reception I was offered by the people of the study area. I appreciate the supportive assistants from Kisiba especially the traditional leaders and Ward government officials for their cooperation during the entire period of the fieldwork. Dr. Charles Saanane is thanked for his encouragements and provision of conducive environments for writing the manuscript of this paper at the Department of Archaeology and Heritage, University of Dar es Salaam in Tanzania. Lastly, I owe Mrs. Linda Sunderland a huge debt for editing the first draft of this paper and giving out critical comments that reshaped and polished the content of the manuscript.

\section{References}

[1] Tanzania National Population Census (1988) Tanzania National Population Census: TZA-NBS-PHC-1988-v01, Dar es Salaam.

[2] Mbeya Region Socio-Economic Profile: Regional Commissioners’ Office 2011.

[3] Maitima, M.J., Simon, M.M., Robin, S.R., Louis, N.G., Majule, A.E., Herbet, L., Dereck, P., Stephen, M. and Sam, M. (2009) The Linkages between Land Use Change, Land Degradation and Biodiversity across East Africa. African Journal of Environmental Science and Technology, 3, 310-325.

[4] Majule, A.E., et al. (2008) Climate Change and Variability: Impacts on Agriculture and Water Resource and Implications for Livelihoods in Selected Basins. Towards Climate Change Adaptation. Inwent-Internationale Weiterbildungund Entwicklungggmbh, Bonn.

[5] Majule, A.E. and Mwakisunga, B. (2010) The Impacts of Land Management Practices on Soil Quality Implications on Smallholder Productivity in Southern Highland Tanzania. Journal of Environmental Economics, 1, 59-67.

[6] Willoughby, P.R. (1996) Middle Stone Age Technology and Adaptation in Southwestern Tanzania. In: Pwiti, G. and Soper, R., Eds., Aspects of African Archaeology, University of Zimbabwe Press, Harare, 177-190.

[7] Willoughby, P.R. (2001) Middle Stone Age Technology from the Lake Rukwa Rift, Southwest Tanzania. South African Archaeological Bulletin, 56, 125-152.

[8] Willoughby, P.R. (2007) The Evolution of Modern Humans in Africa. A Comprehensive Guide, Altamira Press, UK.

[9] Fontijn, K., Ernst, G.G.J., Elburg, M.A., Williamson, D., et al. (2010) Holocene Explosive Eruptions in the Rungwe 
Volcanic Province, Tanzania. Journal of Volcanology and Geothermal Research, 196, 91-110. http://dx.doi.org/10.1016/j.jvolgeores.2010.07.021

[10] Williamson, D., et al. (2012). The Rungwe Volcanic Province, Tanzania-A Volcanological Review. Journal of African Earth Sciences, 63, 12-31.

[11] Mnjokava, T.T. (2006) Geothermal Exploration in Tanzania-Status Report: Geological Survey of Tanzania

[12] Mabulla, Z.P. (2000) Strategy for Cultural Heritage Management (CHM) in Africa: A Case Study. African Archaeological Review, 17, 211-233. http://dx.doi.org/10.1023/A:1006728309962 